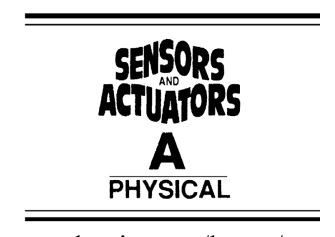

www.elsevier.com/locate/sna

\title{
Fabrication of high temperature surface acoustic wave devices for sensor applications
}

\author{
M.N. Hamidon ${ }^{\text {a,* }}$, V. Skarda ${ }^{\text {a }}$, N.M. White ${ }^{\mathrm{a}}$, \\ F. Krispel ${ }^{\text {b }}$, P. Krempl ${ }^{\text {c }}$, M. Binhack ${ }^{\text {d }}$,W. Buff ${ }^{\mathrm{d}}$

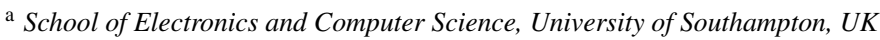 \\ b Piezocryst GmbH, Austria \\ c AVL List GmbH, Austria \\ ${ }^{\mathrm{d}}$ Technische Universitaet Ilmenau, Germany
}

Received 13 September 2004; received in revised form 12 January 2005; accepted 27 January 2005

Available online 26 February 2005

\begin{abstract}
Surface acoustic devices have been shown to be suitable not only for signal processing but also for sensor applications. In this paper high temperature surface acoustic wave devices based on gallium orthophosphate have been fabricated, using a lift-off technique and tested for high frequency applications at temperatures up to $600^{\circ} \mathrm{C}$. The measured S-parameter $\left(\mathrm{S}_{11}\right)$ has been used to study the mass loading effect of the platinum electrodes and turnover temperature of $\mathrm{GaPO}_{4}$ with a $5^{\circ}$ cut. The analysis of these results shows that the mass loading effect can be used to predict the desired resonant frequency of the SAW devices. Also two different adhesion layers for Pt metallisation were studied. Our results show that Zirconium is a more suitable under layer than Titanium.
\end{abstract}

(C) 2005 Elsevier B.V. All rights reserved.

Keywords: Surface acoustic wave; Fabrication; Gallium orthophosphate $\left(\mathrm{GaPO}_{4}\right)$; High temperature

\section{Introduction}

The surface acoustic wave (SAW) effect has been used as the main principle for devices that have been successfully applied to the processing of electrical signals for more than 30 years. They are particularly prevalent in the telecommunication industry because of their high performance, small size, and high reproducibility. Also due to their high accuracy and crystal stability over time, SAW devices are suitable for sensor applications such as pressure sensors, biosensors, temperature sensors and mass sensors.

With the correct choice of materials it is possible to fabricate SAW devices that are capable of operating in high temperature environments up to $600^{\circ} \mathrm{C}$. When operating frequencies are inside the ISM-band (around $434 \mathrm{MHz}$ ), they are of interest to industrial sectors such as aerospace, power

\footnotetext{
* Corresponding author. Tel.: +44 23 8015 93114; fax: +44 2380592901.
}

E-mail address: mnbh01r@ecs.soton.ac.uk (M.N. Hamidon). plants, chemical and petrochemical plants and the nuclear sector. The overall performance of these devices in high temperature applications depends greatly on the choice and cut of the piezoelectric material and the metallisation used [1].

To fabricate the devices that will operate at the frequencies mentioned above, the mass loading effect of the electrode mass has been studied. By adding or reducing the mass of the electrode a convenient means of frequency adjustment can be achieved $[2,3]$. But the device stability especially at high temperatures and in harsh environments also needs to be investigated due to change in performance under such conditions [4].

From a study carried out by Lewis [5], the mass loading effect of a typical piezoelectric plate resonator consisting of a piezoelectric substrate disk, such as quartz with metallic electrodes on the top and bottom, can be written as

$$
R=\frac{\rho_{\mathrm{e}} t_{\mathrm{e}}}{\rho_{\mathrm{s}} h}=\frac{f-f_{\mathrm{e}}}{f}
$$


Table 1

Resonant frequency vs. Pt thickness

\begin{tabular}{llll}
\hline Sample & $\begin{array}{l}\text { Under layer } \\
\text { metal }\end{array}$ & $\begin{array}{l}\text { Platinum } \\
\text { thickness }(\mathrm{nm})\end{array}$ & $\begin{array}{l}\text { Resonant } \\
\text { frequency } \\
(\mathrm{MHz})\end{array}$ \\
\hline W1 & & 135 & 399.05 \\
W2 & $\mathrm{Ti}$ & 72 & 433.90 \\
W3 & & 76 & 439.70 \\
W4 & & 94 & 424.90 \\
W5 & Zr & 75 & 434.90 \\
W6 & & 72 & 436.79 \\
\hline
\end{tabular}

where $\rho_{\mathrm{e}}$ and $t_{\mathrm{e}}$ are the electrodes layer density and thickness, $\rho_{\mathrm{s}}$ and $h$ are the mass density and height of the piezoelectric substrate.

In our case, the electrodes of the resonator were fabricated as an interdigital transducer (IDT) grating consisting of two different layers of material ( $\mathrm{Pt}$ with a Ti under layer). So Eq. (1) has been modified [6] to

$R=$ const. $\left(\frac{\sum \rho_{\mathrm{i}} t_{\mathrm{i}}}{\lambda}\right)^{2}$

where $\rho_{\mathrm{i}}$ and $t_{\mathrm{i}}$ are the density and height of the layer forming the IDT grating and the constant is equal to $0.455\left(\mathrm{~g} \mathrm{~cm}^{-3}\right)^{-2}$, which has been calculated from the research studies performed by Bigler and Briot [7] for surface transverse waves with $\mathrm{Al}$ or gold on $\mathrm{GaPO}_{4}$.

By using this equation the numerical predictions of the resonant frequencies of the devices can be calculated and compared with the experimental results.

\section{Fabrication and materials}

In this paper, a direct write e-beam lithography coupled with a lift-off technique has been used to fabricate interdigital transducers with maximum definition of the device structure, without damaging the surface of the substrate as is the case with ion beam or wet etching techniques [6]. The fabricated devices consist of two-port resonator with each IDT having 50 fingers, 50 wavelength aperture, 200 strips short circuit reflectors and $1.4 \mu \mathrm{m}$ finger width with a 1:1 finger to space ratio.

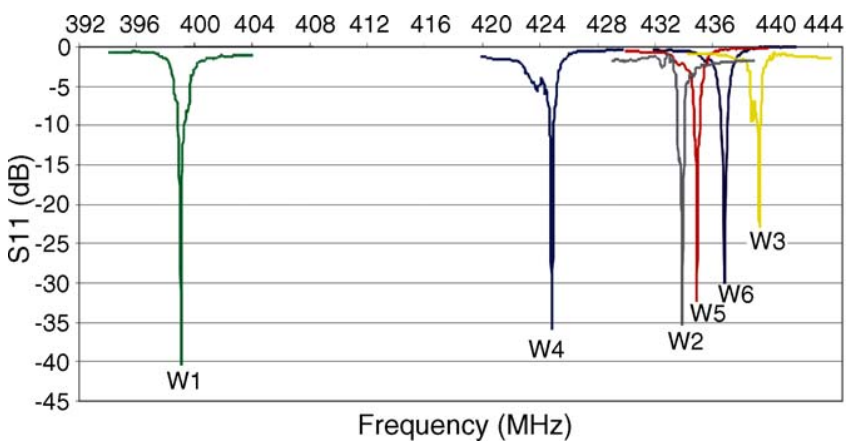

Fig. 1. $\mathrm{S}_{11}$ parameter vs. resonant frequency.
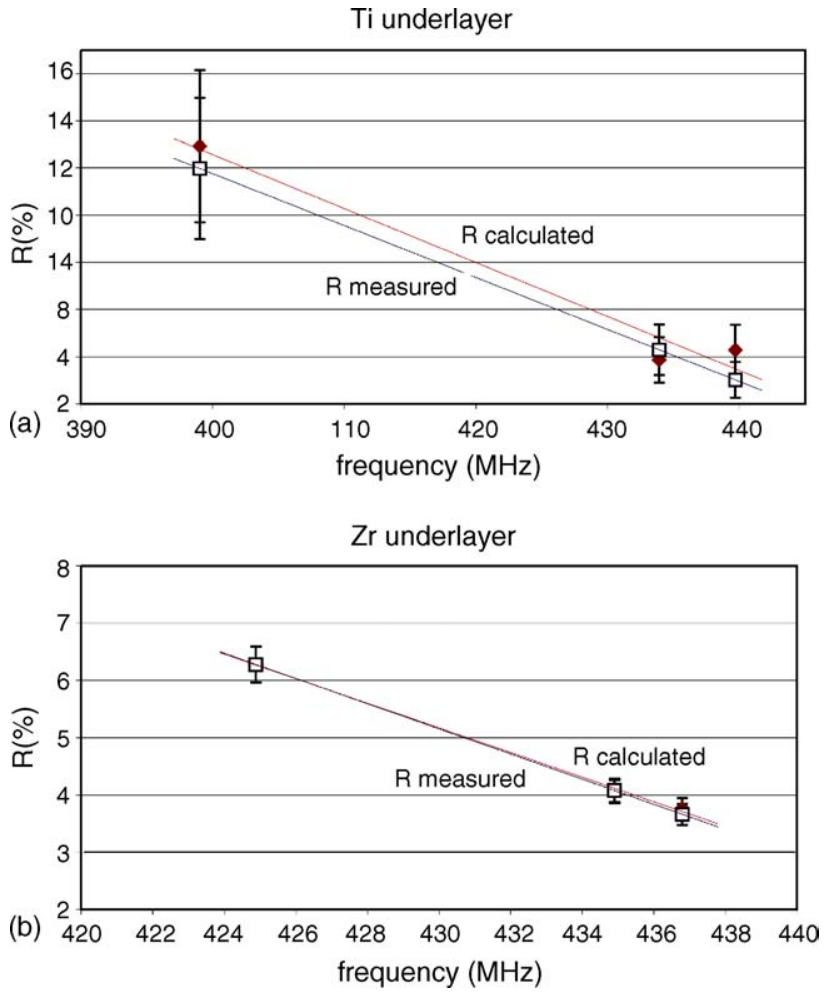

Fig. 2. Mass loading vs. resonant frequency for (a) Ti under layer and (b) $\mathrm{Zr}$ under layer.

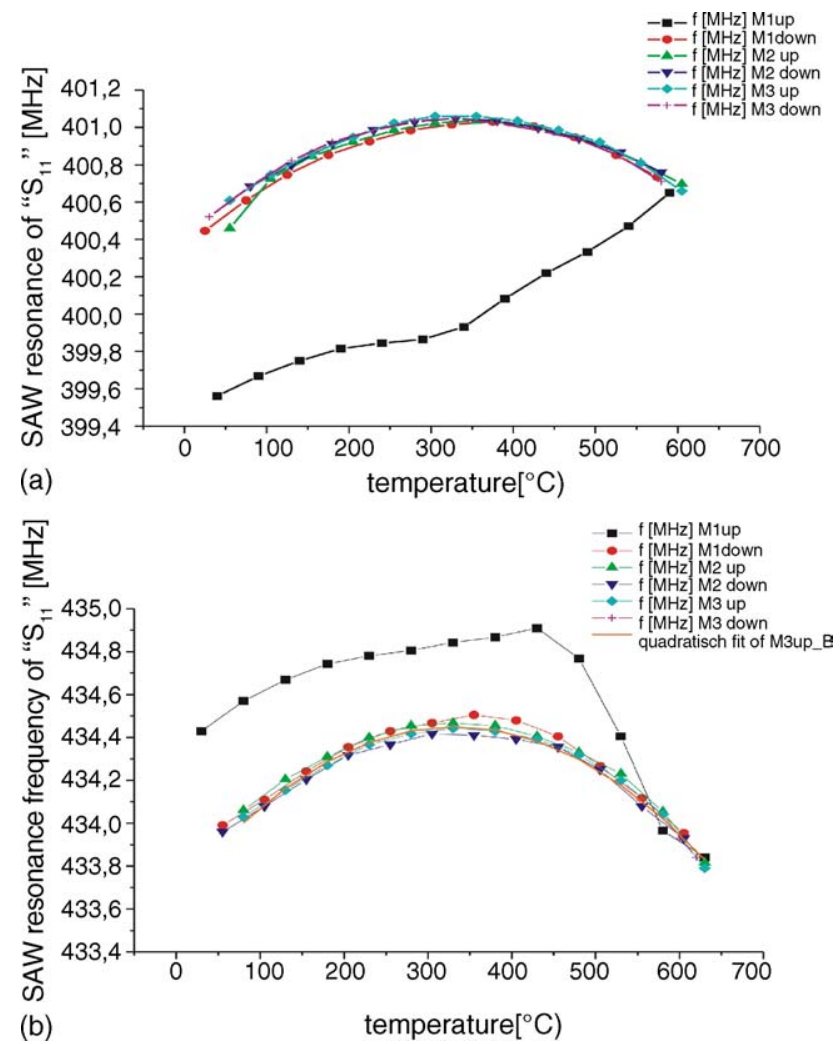

Fig. 3. Temperature dependence of (a) W1 and (b) W2 with Ti under layer. 


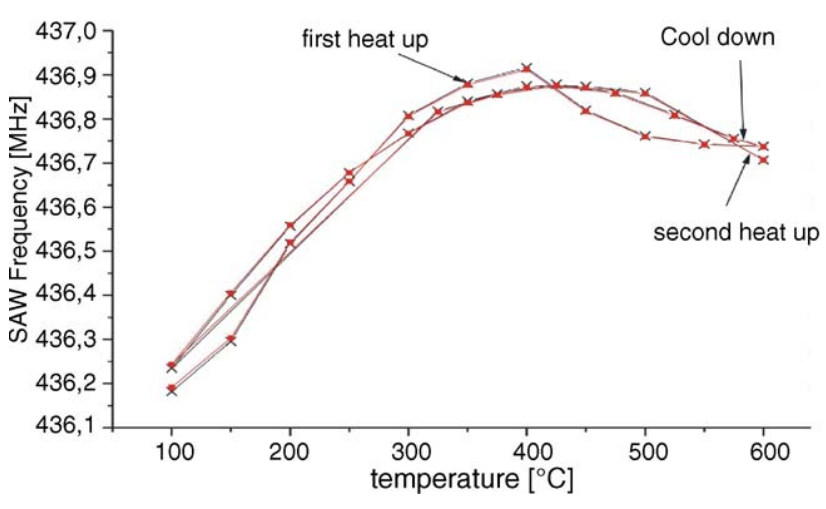

Fig. 4. Temperature dependence of W6 with $\mathrm{Zr}$ under layer.

A new piezoelectric crystal, gallium orthophosphate $\left(\mathrm{GaPO}_{4}\right)$, has been used as the substrate for fabrication. The $\mathrm{GaPO}_{4}$ crystal has a higher electromechanical coupling factor then quartz, lower SAW velocity and a retention of its piezoelectric properties over a very wide temperature range (up to $930^{\circ} \mathrm{C}$ ), which makes this material a better choice than quartz for high temperature piezoelectric devices [8].

The resonant frequency of $\mathrm{GaPO}_{4}$ is less sensitive to the cut angle $\theta$, which means that it has lower angular sensitivity and by having a larger bandwidth, the resonant frequency can vary within a wider range [9]. In this work, a new cut of $\mathrm{GaPO}_{4}$ crystal orientation has been used, which is known as Y-Boule orientations with a $5^{\circ}$ cut. An additional advantage of the $\mathrm{GaPO}_{4}$ devices is their self-cleaning property when

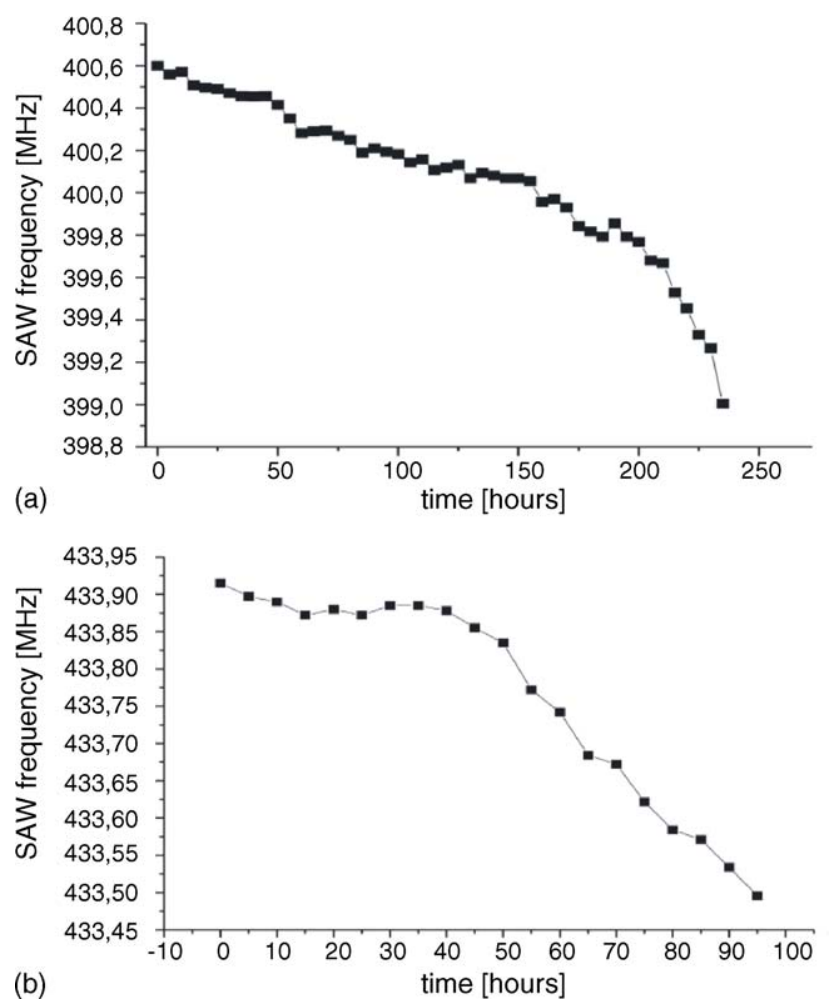

Fig. 5. Long-term resonant frequencies stability of (a) W1 and (b) W2 with Ti under layer. they are heated up to $600^{\circ} \mathrm{C}[10]$. The surface of the resonator is automatically cleaned while operating at high temperature. To date, sizes of $3.5 \mathrm{~cm} \times 4.5 \mathrm{~cm} \mathrm{GaPO}$ crystal wafers were available which are the largest size wafers available worldwide. This facilitates the fabrication of devices with fine features when compared to the earliest size of the crystal wafers studied for this application (from 1 to $4 \mathrm{~cm}^{2}$ depending on the crystal cut) [11].

Platinum $(\mathrm{Pt})$ has been chosen for the electrode metallisation because of its high melting temperature $\left(1768.3^{\circ} \mathrm{C}\right)$, resistance to oxidation and nearly constant bulk resistance temperature coefficient. For good adhesion, a titanium (Ti) or zirconium $(\mathrm{Zr})$ under layer between the $\mathrm{Pt}$ and the $\mathrm{GaPO}_{4}$ wafer was used for the study. Three different Pt thickness as shown in Table 1 with the constant $20 \mathrm{~nm}$ Ti under layer have been used as a metallisation to study the mass loading effect and compare it with numerical predictions. Also in Table 1, three different Pt thicknesses with the constant $10 \mathrm{~nm} \mathrm{Zr}$ under layer were used for the same study.

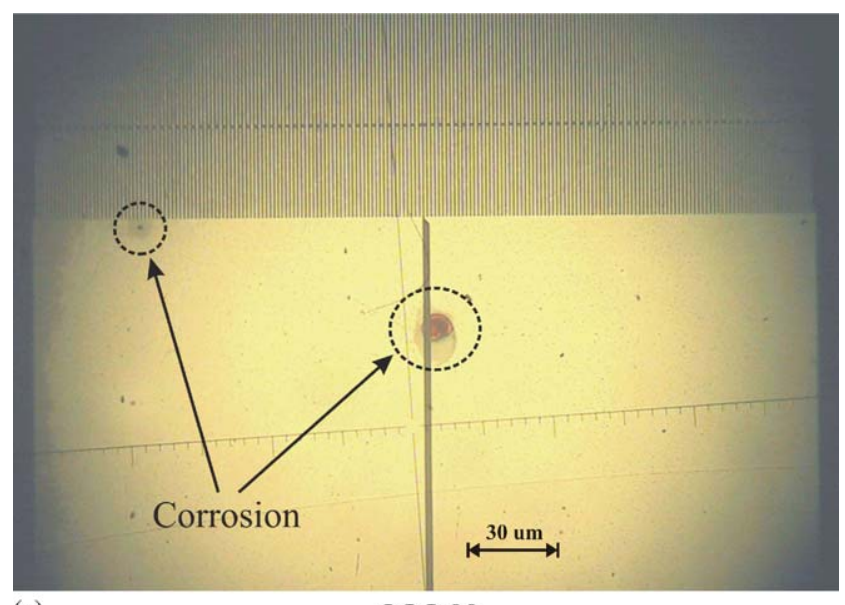

(a)
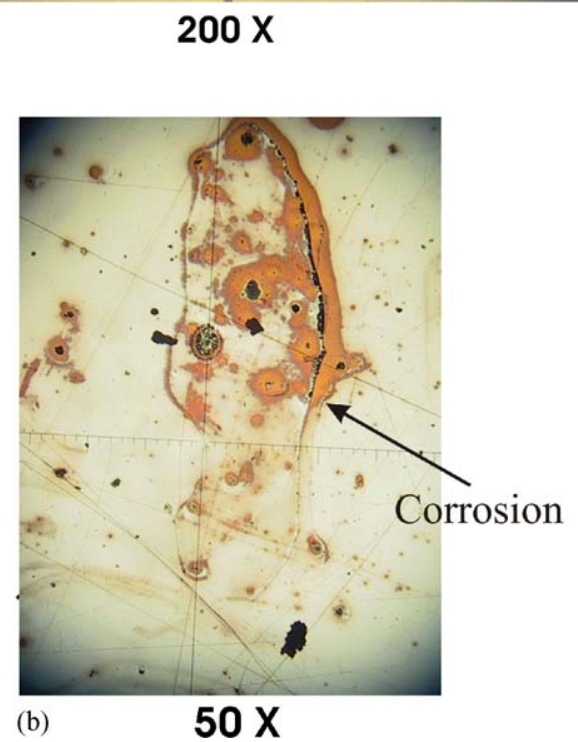

Fig. 6. The corrosion of a Ti under layer for SAW devices kept at (a) $600^{\circ} \mathrm{C}$ for $192 \mathrm{~h}$ and (b) $800^{\circ} \mathrm{C}$ for $120 \mathrm{~h}$. 


\section{Results}

By observing the $S_{11}$ parameter, the change in resonant frequency with different Pt thickness can be observed and these are summarised in Table 1 and Fig. 1. In Fig. 2, the relative mass loading effect (expressed as a percentage change) due to different thickness is plotted against measured resonant frequencies of the SAW resonators, where Fig. 2(a) with Ti under layer and Fig. 2(b) with $\mathrm{Zr}$ under layer. It was found that by using the effect of mass loading on the resonant frequency of the devices [3], the required operation at $434 \mathrm{MHz}$ for ISM-band could be achieved from both under layers.

Two different Pt thickness (W1 and W2) for the Ti under layer, in the SAW metallisation were used to study the effect of thickness on the temperature turnover in the region where the temperature dependence of the resonant frequency starts to decrease. It was found that the differences in Pt thickness do not affect the turnover temperature to a great extent as shown in Fig. 3. Both devices have nearly the same turnover temperature at $350^{\circ} \mathrm{C}$. The sample W6 with $\mathrm{Zr}$ under layer has higher turnover temperature at $430^{\circ} \mathrm{C}$ as shown in Fig. 4.

In Fig. 5 the resonant frequencies are plotted against time for W1 and W2. It was found that the calculated relative drifts of the frequencies were $10 \mathrm{ppm} / \mathrm{h}$ for $\mathrm{W} 1$ and $18 \mathrm{ppm} / \mathrm{h}$ for W2. One of the reasons for the drift was the gold bonding due to diffusion of gold wire into the Pt electrodes, which in turn influenced the behaviour of both devices [12]. Further the Ti under layer also oxidised at a high temperature during long periods of annealing as shown in Fig. 6(a). The sample was kept at $600^{\circ} \mathrm{C}$ for $192 \mathrm{~h}$ and the oxidation was much more pronounced after $120 \mathrm{~h}$ at $800^{\circ} \mathrm{C}$ as shown in Fig. 6(b). Also in Fig. 5, the decrease of both resonant frequencies for $\mathrm{W} 1$ and W2 is shown against time. This is thought to be due to gradual diffusion of gold into the IDT pad in addition to corrosion of Ti under layer at high temperatures as shown in

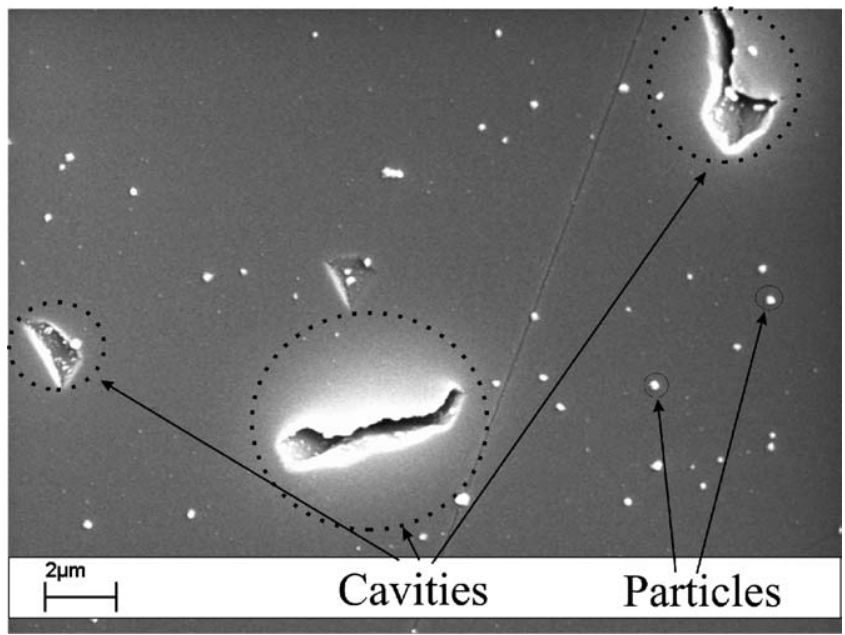

Fig. 7. SEM picture of W6 after $144 \mathrm{~h}$ under $600^{\circ} \mathrm{C}$.

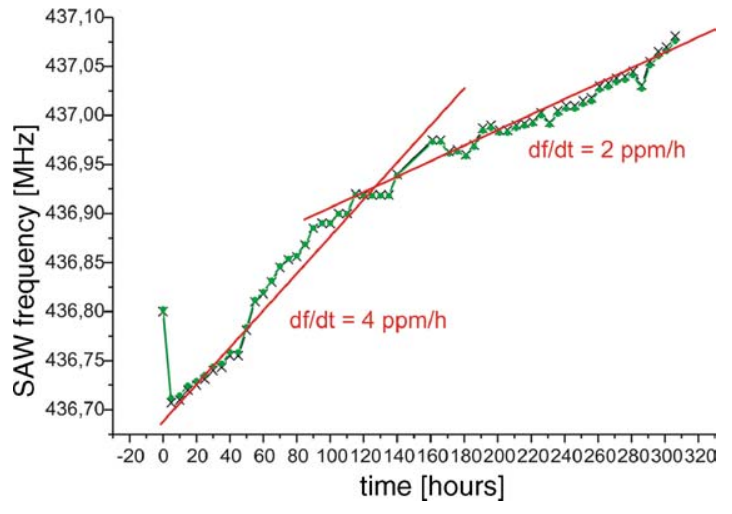

Fig. 8. Long-term resonant frequencies stability of $\mathrm{W} 6$ with $\mathrm{Zr}$ under layer.

Fig. 6. By using $\mathrm{Zr}$ as an under layer, however, the devices were more stable at $600^{\circ} \mathrm{C}$ as shown in Fig. 7. The appearance of the white specks in the figure indicates the presence of dust particles, probably from the inner coating of the oven used in the experiments. The presence of cavities is also been identify in Fig. 7, and these are caused by defects within the $\mathrm{GaPO}_{4}$ substrate surface.

In Fig. 8, the resonant frequencies are plotted against time for W6 and it was found that the calculated relative drifts of the frequencies was $2 \mathrm{ppm} / \mathrm{h}$, which is an improvement over the samples $\mathrm{W} 1$ and $\mathrm{W} 2$. Also this value is positive due to the increasing values of the resonant frequencies. This also means that the effect of mass loading of the devices was decreased. In this case, there was no diffusion between the wire and the pads because Pt wire was used for the bonding.

\section{Conclusions}

In this work, a model of the mass loading versus resonant frequency for $\mathrm{Pt}$ with $\mathrm{Ti}$ and $\mathrm{Zr}$ under layer has been presented and compared with the literature. It was found that by using established theory presented in the literature, the desired resonant frequency of the SAW devices could be predicted for each case.

The high temperature behaviour of the SAW devices has been studied for the new cut. The $S_{11}$ parameter has been shown to be stable over multiple temperature cycles and independent of the electrode thickness. For improved long-term stability the thicker Pt electrode is more stable, compared to the thinner sample due to Au wire diffusion and an oxidation of the Ti under layer of the electrodes. Devices with $\mathrm{Zr}$ under layer were more stable and further investigations are being undertaken.

\section{Acknowledgement}

This work was supported by the European Commission under grant G1RD-CT-2001-00541 "WIREGONE". 


\section{References}

[1] K.A. Snook, J.-Z. Zhao, C.H.F. Alves, J.M. Cannata, W.-H. Chen, R.J. Meyer, T.A. Ritter, K.K. Shung, Design, fabrication and evaluation of high frequency, single-element transducers incorporating different materials, IEEE Trans. Ultrasonics Ferroelectr. Frequency Control 49 (2002) 169-176.

[2] S. Mallikarjum, J. Kosinski, A. Ballato, Mass loading measurements of quartz crystal plate, in: Proceedings of the IEEE Frequency Control Symposium, 1989, pp. 365-371.

[3] A. Ballato, J. Kosinski, T. Lukaszek, Temperature and angular variations of piezoelectric coupling in quartz, in: Proceedings of the IEEE Frequency Control Symposium, 1988, pp. 353-356.

[4] R.L. Filler, J.R. Rig, Fundamental mode SC-cut resonators, in: Proceedings of the IEEE Frequency Control Symposium, 1980, pp. $187-193$.

[5] O. Lewis, Relationship of resonant frequency of quartz crystal to mass loading, in: Proceedings of the IEEE Frequency Control Symposium, 1975, pp. 5-9.

[6] Project Funded by European Community Under the IMT Programme, Remote Monitoring of Strain Extension Using a Novel Sensing Element, Contract Number: BRPR-CT96-0361, 2000.

[7] E. Bigler, J.-B. Briot, A comparison of surface transverse wave propagation on quartz and gallium orthophosphate, Forum ASA/AEE, 1999.

[8] D. Palmier, R. Gohier, C. Bonjour, G. Martin, A. Zarembovitch, E. Bigler, E. Philippot, New results on the thermal sensitivity of bulk and surface modes of gallium orthophosphate $\mathrm{GaPO}_{4}$, in: Proceedings of the IEEE Frequency Control Symposium, 1995, pp. 605-610.

[9] E. Benes, M. Groschl, F. Seifert, A. Pohl, Comparison between BAW and SAW sensor principles, IEEE Trans. Ultrasonics Ferroelectr. Frequency Control 44 (1998) 1314-1330.

[10] H. Thanner, P.W. Krempl, F. Krispel, C. Reiter, R. Selic, High temperature microbalance based on $\mathrm{GaPO}_{4}$, Ann. Chim. Sci. Mat. 26 (2001) 161-164.

[11] E. Bigler, S. Ballandras, C. Bonjour, D. Palmier, E. Philippot, Experimental study of saw propagation on gallium orthophosphate, in: Proceedings of the IEEE Frequency Control Symposium, 1994, pp. 385-389.

[12] W. Buff, M. Binhack, S. Klett, M. Hamsch, R. Hoffmann, F. Krispel, W. Wallnofer, SAW resonators at high temperature, in: Proceedings of the IEEE Frequency Control Symposium, 2003, pp. 187-191.

\section{Biographies}

Mohd. Nizar Hamidon received BSc degree in Physics in 1994 from Universiti Malaya, Malaysia and MSc degree in Microelectronic in 2001 from Universiti Kebangsaan Malaysia, Malaysia, and now working as an academic staff at Universiti Putra Malaysia, Malaysia. He is currently working toward $\mathrm{PhD}$ at School of Electronic and Computer Science at
University of Southampton. His research interests are microelectronic fabrication and wireless devices related to sensor applications.

Vlad Skarda received his MSc in 1973 and his PhD in Nuclear Science and Physical Engineering from Czech Technical University of Prague in 1976. Following his three years NSF Research fellowship in the United States, where he was working on polymeric semiconductors and liquid crystal displays, he spent 15 years as a Manager of the Microsystems Department at ERA Technology in England working on the development of a variety of novel integrated optical, microelectronic and microengineered products. He joined Electronics Department at Southampton University in 2001, where he is currently involved in the development of high temperature SAW devices for plant monitoring application.

Neil White obtained the degree of PhD from the University of Southampton in 1988. He was appointed as Lecturer in 1990, Senior Lecturer in 1999, Reader in 2000 and is currently Professor of Intelligent Sensor Systems within the School of Electronics and Computer Science at University of Southampton.

Ferdinand Krispel received his MSc in physics from the University of Graz in 1991. Then he joined AVL and is now development engineer for $\mathrm{GaPO}_{4}$ single crystal applications in Piezocryst.

Peter Krempl received his PhD in Physics from University of Vienna, Austria in 1975, a Fellow at CERN, Geneva from 1973 to 1976, Head of Physics Research at AVL List GmbH, Graz since 1976, venia docendi at University of Graz, Austria in 1995 and received IEEE C.B. Sawyer Award in 2003. He is now as an Executive of the "Physics-IndustryEnergy" division of the Austrian Physical Society.

Micheal Binhack was born in Frankfurt, Germany on February 24 in 1971. He studied Microelectronics and Sensor Technologies at the Technial University of Ilmenau from 1993 to 1998. He works as a scientific assistant at the Institute of Solid State Electronics at the Faculty of Electrical Engineering and Information Technology since 1998. His research interests are mainly passive wireless sensors based on SAW resonators for extreme environments.

Werner Buff received his Dipl-Ing, Dr-Ing and Dr-Ing habil degrees from the Technische Hochschule Ilmenau (now Technische Universität Ilmenau, Thüringen) in 1968, 1974 and 1984 respectively. Prior to joining the Technische Hochschule Ilmenau as assistant, he was in charge for an $R \& D$ group in the industry in the field of temperature measurement elements. Until he retired at the end of March 2004, he was a professor in the Faculty of Electrical Engineering and Information Technique at the TU Ilmenau and the head of the Laboratory of Semiconductor Sensors. He was teaching the fundamentals of electronics and some special courses. His research interest has been in surface acoustic waves (SAW) and their application in sensors since about twenty years. His current activities are focused on SAW sensor systems with remote measurement capabilities in a passive wireless manner while he is the CEO of the company senTec Elektronik GmbH in Ilmenau, Germany. Prof. Buff was a senior member of the IEEE Ultrasonics, Ferroelectrics and Frequency Control Society. 